\title{
Interpretación de retruécanos, imágenes de doble sentido y bromas en el arte paleolítico
}

\section{The interpretation of puns, jokes and double meaning images in Palaeolithic art}

\author{
Alberto Lombo Montañés \\ Facultad de Filosofía y Letras. Área de Prehistoria \\ Universidad de Zaragoza \\ albertrisa13@hotmail.es
}

Recibido: 21-07-2013

Aceptado: 21-10-2013

\begin{abstract}
RESUMEN
En el presente artículo pretendemos interpretar algunas grafias del arte paleolítico utilizando los conceptos de retruécano visual e imagen de doble sentido aplicados por Barbara Olins Alpert (1992). También explicamos otras grafías como exhibiciones fálicas o anales comparándolas con bromas de los pueblos ágrafos.
\end{abstract}

Palabras Clave: Arte paleolítico, Europa, Retruécano, Doble sentido, Bromas.

\begin{abstract}
In this paper, some graphics units of Paleolithic art are interpreted as visual pun and double entendre images. These concepts have already been applied by Barbara Olins Alpert (1992). Other motifs are also explained such as anal or phallic forms comparing jokes with preliterate people.
\end{abstract}

KEY WoRDs: Palaeolithic art, Europe, Pun, Double entendre, Jokes. 


\section{Introducción}

\subsection{Estado de la cuestión}

La interpretación de retruécanos, imágenes de doble sentido y bromas es minoritaria y reciente en la historiografía del arte paleolítico. Estos aspectos del arte jamás fueron estudiados por los prehistoriadores decimonónicos (Lartet y Christy, Piette y Mortillet) que consideraban lo lúdico como algo simple e ingenuo (Richard 1993: 60-61).

Durante la primera mitad del siglo XX los nuevos hallazgos de grafías de época paleolítica fueron interpretados mediante comparaciones etnográficas (Reinahc 1903; Cartailhac y Breuil 1906) que priorizaron los aspectos religiosos más extravagantes de las religiones de los pueblos "primitivos" (Evans-Pritchard 1988: 21-22). Las explicaciones incluían todo tipo creencias de índole religiosa: tótems (Cook 1903), antepasados (Wernert 1916), magia (Bégouën 1929), sin tener en cuenta los aspectos cotidianos o lúdicos en sus comparaciones. Los estudios en antropología sobre el humor son relativamente recientes (Driessen 1999) y en contadas ocasiones se tienen en cuenta figuras como la de los payasos sagrados (Campbell 1991: 98) o el Trickster de las mitologías (Radin 1969) que se encuentran relacionados a bromas anales y fálicas de carácter exhibicionista (Campbell 1991: 226-227;Barley 2010: 108).

La palabra calembour (retruécano) la utiliza por primera vez Luquet (1926: 156) para describir la doble imagen de un falo y un coleóptero en el bastón fálico de Gorge d'Enfer. En la década de los ochenta Carpenter descubre el uso de retrúecanos visuales entre las producciones artísticas de las poblaciones esquimales (Carpenter 1980: 72).Y diez años después Olins Alpert los identifica en las grafías parietales y mobiliares paleolíticas, pero establece una diferencia entre retruécanos visuales e imágenes reversibles muy difícil de apreciar (Olins Alpert 1992: 220-228).

Las figuras de doble sentido nunca han sido estudiadas de manera concreta salvo en una ocasión (Olins Alpert 1992: 228-231). Esta autora incluye en este tipo de representaciones las grafías que juegan con las formas de las paredes de las cuevas. Plassard (1999: 71) ha destacado el aspecto humorístico de algunas de estas grafías en la cueva de Rouffignac. En concreto destacan la cabeza de un caballo inscrita en un riñón de sílex y otro caballo con dos ojos naturales (Plassard 1999: figs. 1 y 80). Aunque estas figuras que utilizan las formas de las paredes de las cuevas han sido la mayoría de las veces interpretadas desde un enfoque religioso (p. e. Sauvet y Tosello1999).
Las bromas han sido aún más difíciles de identificar. En 1963 Péquart describió como una broma cómica la escultura de un cervatillo que vuelve la cabeza para mirar como unos pájaros se posan sobre sus heces en un propulsor de Mas d'Azil (Péquart y Péquart, 1963. 330) y así fue interpretado (Laurent 1965; Delporte 1990: 152) éste y otros propulsores pirenaicos análogos hasta hace unos años (Clottes 2001).

\subsection{Justificación del estudio}

Lo que conocemos como arte paleolítico es un variado repertorio de vestigios arqueológicos que se extienden por el vasto continente europeo a lo largo de casi treinta mil años. Este conjunto de obras parietales y muebles "contiene y expresa los anhelos y deseos, las alegrías y tristezas, los ideales y los fines de la humanidad" (Obermaier 1932: 78). Incluso una misma caverna alberga figuras de muy distinto carácter, probablemente correspondientes a distintas motivaciones y significados (González Sainz 2005: 193-194). Sin embargo el arte paleolítico ha sido explicado hasta hace unos treinta años mediante un único componente: la religión (Balbín 2005: 23). Algunos autores han resaltado la quiebra de esta interpretación religiosa o paradigma funcionalista sagrado (Palacio-Pérez 2010; Hernando Álvarez 2012: 42) y cómo esta explicación unívoca ha colapsado otras posibles vías interpretativas (Balbín y Alcolea 1999; Bahn 2003: 63; Balbín 2005). Uno de estos caminos puede ser el de reinterpretar las grafías desde un renovado enfoque lúdico. El juego es un componente esencial de cualquier mitología o creencia religiosa (Huizinga 1968) y es además un mecanismo imprescindible en la creación artística (Halvestron 1987). Resultaría extraño que las sociedades paleolíticas no hubieran dejado huellas de este particular estado de ánimo. La alegría es una emoción universal y fundamental para la comunicación (Ver p. e. Eibl-Eibesfeldt 1993: 506-508) que se expresa de forma gráfica en todas las sociedades humanas de muy diversas maneras.

\section{Objetivo y método}

Nuestro objetivo es profundizar en la definición y clasificación de estos tipos de juegos gráficos para intentar identificar expresiones del sentido del humor en las sociedades paleolíticas.

El retruécano verbal es un juego de palabras que consiste en la inversión de los términos para provocar un contraste de sentidos (Freud [1905] 


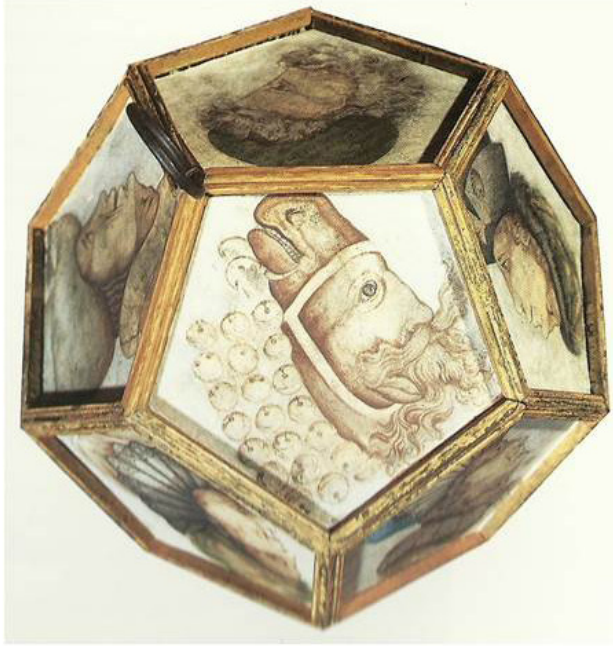

A

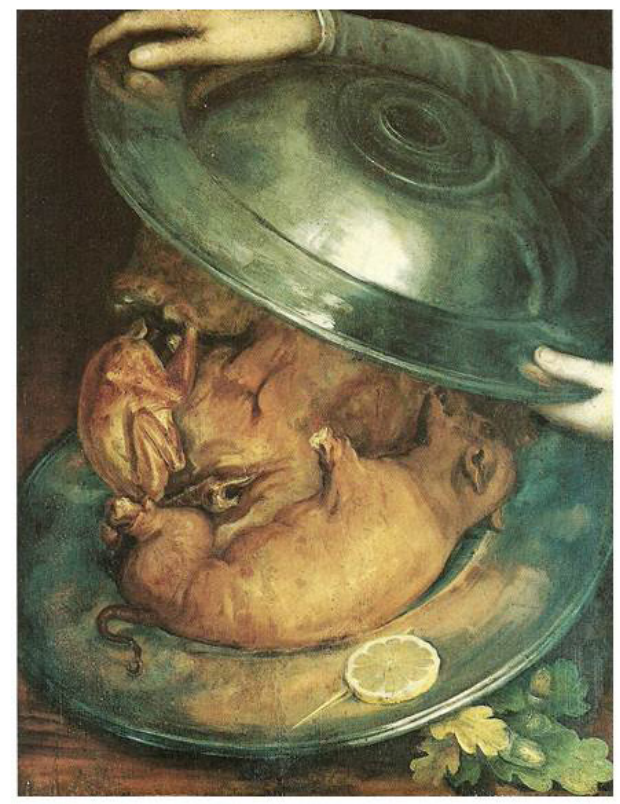

Figura 1.- Ejemplos del arte moderno. A. Juego anónimo (siglo XVI) obsérvese que un mismo ojo es utilizado para dos cabezas diferentes de caballo y humana (Fučková 1987: 132). B. El cocinero óleo reversible (1570) del pintor italiano Arcimboldo (Rheims 1987: 119).

1970). En lo visual puede traducirse por una inversión de figuras para provocar un contraste de orientación. En el arte mueble paleolítico existe un pequeño grupo de grafías de zoomorfos que aparecen en posiciones inversas. Estas piezas son reversibles, es decir, al girarlas $180^{\circ}$ una de las grafías conserva siempre su orientación natural. Existen ciertas condiciones en las que estas grafías mobiliares presentan analogías con los retruécanos visuales. Hemos descartado las piezas que presentan en una misma cara asociaciones de tres o más figuras zoomorfas casi siempre superpuestas, que quizá aludan a otro tipo de motivaciones diferentes a las reversibles (Ver Sieveking 1988). De esta forma entendemos por retruécano gráfico las piezas de arte mueble que contienen en una misma cara figuras en posición inversa (reversibles), cuyas grafías zoomorfas están en asociación dual y en orientación divergente vertical (Fig. 2).

Esta definición permite obtener una mayor precisión en la intención de hacer el objeto para ser visto por los dos lados y menos en otras motivaciones casuales o simbólicas.

El doble sentido sólo puede detectarse a nivel material en figuras que juegan con las formas gráficas, o bien en las figuras que comparten un mismo elemento de elaboración gráfica o accidente natural de una superficie parietal (relieve, grieta, estalagmita, etc.). La forma de dicho elemento o accidente tiene que tener un doble sentido: puede representar un ojo y un ano, un pene y una estalactita al mismo tiempo (Figs. 3. B y A respectivamente). Hemos descartado las superposiciones que pudieran ser fruto de otras figuras o incluso de la representación del movimiento (Azéma1992). Así pues, consideramos como imágenes de doble sentido aquellas figuras que comparten claramente un mismo elemento gráfico o accidente natural significativo.

La Real Academia de la Lengua (2001: 1263) define broma en su acepción segunda como "chanza, burla". Para detectar una broma hemos utilizado una estrategia diferente. Nos basamos en dos aspectos fundamentales del dibujo humorístico: la incongruencia (Puche y Lozano 2002: 113) y la exageración (Olins Alpert 1992: 231). Utilizamos las analogías con bromas universales del género humano y en particular de las poblaciones ágrafas. Hemos interpretado como exhibición fálica o anal (escatológica) aquellas representaciones de humanos o antropomorfos que presentan un falo exagerado, o que encontrándose en una posición inclinada, muestran un elemento gráfico directamente asociado a la zona del ano (¿materia fecal?).

Esta definición puede ayudar a explicar ciertas representaciones incongruentes del repertorio grafico parietal. 
A
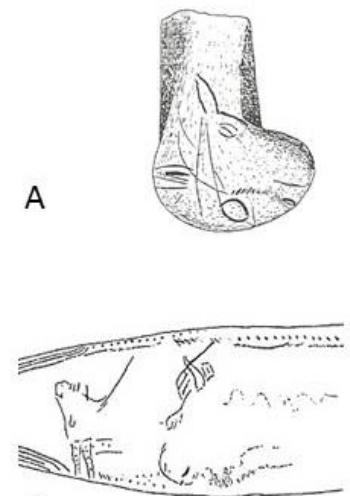

B

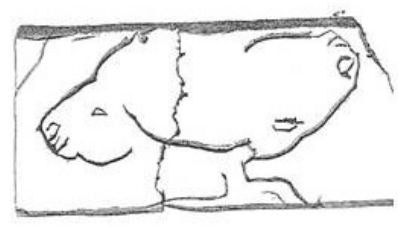

C
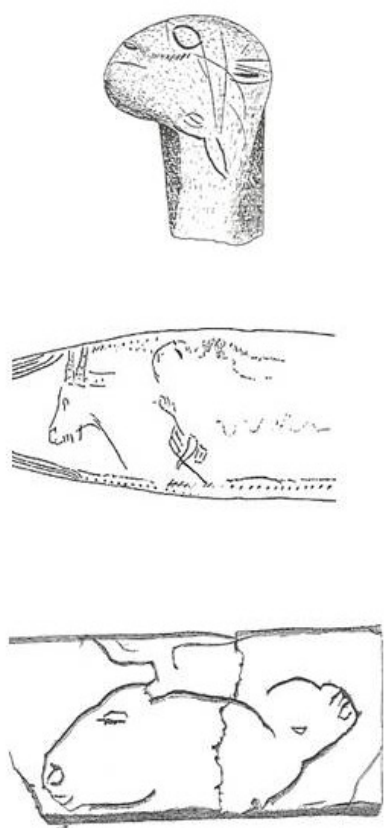
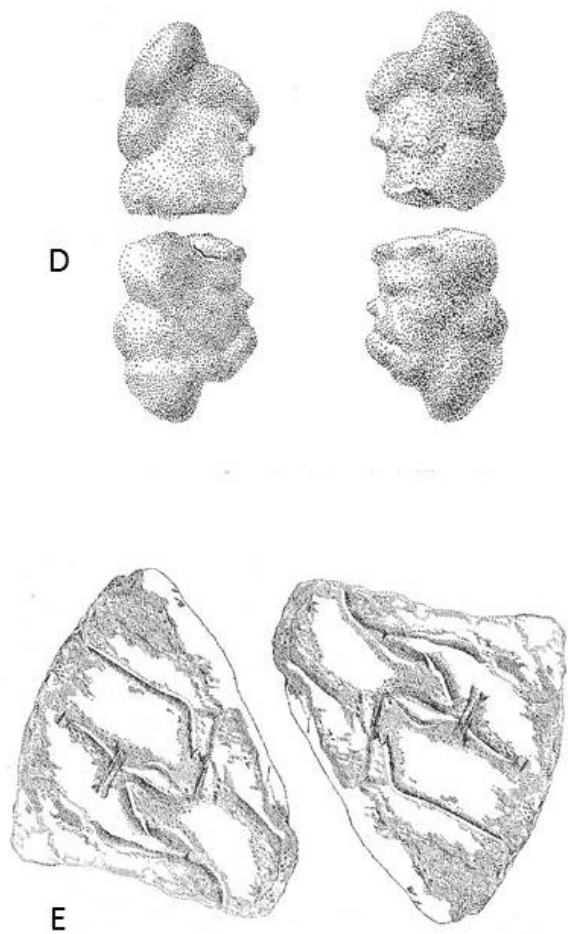

Figura 2.- Piezas reversibles. A. Grotte des Eyzies, cabeza de caballo e indeterminada en un guijarro de esquisto (Tosello 2003: 52, fig. 12. 7). B. Pekarna, conjunto gráfico reversible de cabeza de cabra y bisonte sobre espátula (Lázničková-Gonyševová 2002: 544, fig. 8). C. Gourdan, cabezas de bóvidos reversibles en un fragmento de costilla (Piette 1907: 73, fig. 59). D. Durif, cabeza humana reversible en nódulo de hierro (Pales y Tassin de Saint Péreuse 1979: 118, ob. $\mathrm{n}^{\circ}$ 2, fig. 22). E. Laugerie-Basse, bloque pétreo con figuras reversibles de uro y reno (Giedion [1964] 2003: 581 y 582, figs. 446 y 447).

\section{Los retruécanos gráficos}

Hemos recopilado un pequeño repertorio de veinticuatro piezas reversibles que responden a la definición de retruécano propuesta, teniendo en cuenta: la cronología, la materia prima del soporte, la técnica, la temática zoomorfa (y naturaleza de la asociación dual) y el formato (Tabla 1).

Todas estas piezas pertenecen al periodo tecnocomplejo del Magdaleniense medio y superior salvo dos casos excepcionales: una plaqueta de Parpalló datada en el nivel Solutrense/Gravetiense III, que es también la única realizada en técnica mixta (grabado y pintura), y otra pieza de Lausell también bastante original en cuanto a la concepción simétrica de los cuerpos humanos asociados (que recuerda a una baraja de naipes).

El soporte más utilizado es el lítico (14 casos), seguido del óseo ( 7 casos), asta ( 2 casos) y un nódulo de hierro. Esta última pieza es una piedrafigura encontrada en el nivel IX del abrigo de Durif (Fig. 2.D) que hemos recogido por su carácter reversible (Pales y Tassin de Saint Péreuse1979: 119).

La técnica más utilizada es el grabado (19 casos), seguido del bajo relieve (3 casos) y la técnica mixta ( 1 caso).

La figura zoomorfa más representada es el caballo (10 casos), después el bisonte ( 8 casos), el reno (6 casos), el ser humano (4 casos), la cabra (2casos), el pez (2 casos), la cierva (2 casos), el jabalí (2 casos) y dos bóvidos y felinos sin especificar. Además de un rinoceronte, un uro, una foca, un cánido sin especificar, un lobo e indeterminados (indet.).

Estos zoomorfos pueden estar asociados a figuras de la misma o distinta especie. La asociación dual de zoomorfos de la misma especie aparece en 14 ocasiones, de entre las cuáles la asociación doble de caballos y bisontes aparece tres veces. La asociación dual de zoomorfos de distinta especie aparece en 10 ocasiones con combinaciones entre las que domina el reno: reno y uro, reno y caballo ( 2 casos) y reno e indeterminado. 


\begin{tabular}{|c|c|c|c|c|c|c|}
\hline & Cronología & Soporte & Técnica & Tema & Formato & Bibliografía \\
\hline Brasempouy & Mag. sup. & Hueso & Grabado & Caballos & Cabezas & Piette 1907: pl. LXXVII \\
\hline Colombière & Mag. sup. & Lítico & Grabado & Rinoc y cabra & Ent./me. & Sieveking 1987a: 96, fig. 17 \\
\hline Colombière & Mag. sup. & Lítico & Grabado & Felinos & Me./ca. & Nougier y Robert 1968: 36 \\
\hline Courbet & Mag. sup. & Asta & Grabado & Reno y caballo & Cabezas & Sieveking 1987b: pl. 62.458 \\
\hline Durif & Mag. med. & Hierro & & Humanos & Cabezas & Pales y Tassin de Saint Péreuse 1979: 118, 0bs. 2 \\
\hline Espelegues & Mag. sup. & Lítico & Grabado & Caballo y reno & Enteros & Sieveking 1988: 44, fig. 4 \\
\hline Eyzies/Les & Mag. sup. & Lítico & Grabado & Caballo e indet. & Cabezas & Tosello 2003: 52, fig. 12.7 \\
\hline Fontalès & Mag. sup. & Hueso & Grabado & Cánido y bisonte & Ca./med. & Welté 1988: 201, fig. 2.c \\
\hline Gourdan & Mag. med. & Hueso & Grabado & Bóvidos & Cabezas & Piette 1907: 74, fig. 59 \\
\hline Isturitz & Mag. med. & Hueso & Grabado & Bisontes & Cabezas & Saint-Périer 1936: 111, fig. 63.4 \\
\hline Isturitz & Mag. med. & Hueso & Grabado & Bisontes & Cabezas & Saint-Périer 1936: 111, fig. 63.6 \\
\hline Isturitz & Mag. med. & Lítico & Bajo relieve & Reno e indet. & Medios & Saint-Périer 1930: 105, fig. 90 \\
\hline Laugerie-Basse & Mag. med. & Lítico & Bajo relieve & Uro y reno & Enteros & Gideion [1964] 2003: 581, fig. 446 \\
\hline Laussel & Gravetiense & Lítico & Bajo relieve & Humanos & Medios & Leroi-Gourhan 1971: 356, fig. 273 \\
\hline Madeleine/ La & Mag. med. & Lítico & Grabado & Peces & Enteros & Tosello 2003: 354, fig. 238 \\
\hline Marche/La & Mag. med. & Lítico & Grabado & Caballos & Cabezas & $\begin{array}{l}\text { Pales y Tassin de Saint Péreuse 1981: ob. } \\
\text { 17, pl. } 17\end{array}$ \\
\hline Montastrue & Mag. sup. & Lítico & Grabado & Caballo y lobo & En./med. & Sieveking 1987: 93: fig. 16.a \\
\hline Montastruc & Mag. sup. & Lítico & Grabado & Renos & En./med. & Sieveking 1987: 4: fig. 2 \\
\hline Montastruc & Mag. sup. & Lítico & Grabado & Bisontes & Enteros & Sieveking 1987: pl. 92 y 93.661 \\
\hline Parpalló & Sol./Grav. & Lítico & Mixta & Caballos & Me./cab. & Villaverde 1994: fig. 176, 18705 \\
\hline Parpalló & Mag. sup. & Lítico & Grabado & Jabalís & Enteros & Villaverde 1994: fig 234, 19989 \\
\hline Pekarna (B) & Mag. sup. & Hueso & Grabado & Cabra y bisonte & Cabezas & Lázničková-Gonyševová 2002: 544, fig. 8 \\
\hline Pendo (A) & Mag. sup. & Asta & Grabado & Ciervas & Cabezas & Barandiarán 1984: 137, fig. 10 \\
\hline Vache/La & Mag. sup. & Hueso & Grabado & Foca e ind & Cabezas & Fritz 1999: 116, fig. 109 \\
\hline
\end{tabular}

Tabla 1.- Repertorio de piezas reversibles.

Hemos dividido en tres los formatos de las figuras (cabeza, medio y entero) ${ }^{1}$. El más utilizado para realizar grafías inversas es el formato cabeza (11 casos), seguido del formato entero (5 casos). El resto son combinaciones entre enteros, cabezas y medios.

\subsection{Las imágenes de doble sentido}

Hemos recogido seis ejemplos de figuras que parecen jugar con las formas de los elementos gráficos o las protuberancias de la caverna. Recogemos en el cuadro la naturaleza grafica o natural del elemento compartido por la/s figuras ${ }^{2}$.

En los ejemplos del cuadro observamos como este tipo de representaciones actúa sobre figuras dobles o individuales. En Ambrosio, Fontanet y La Marche dos figuras diferentes comparten un mismo elemento gráfico, de forma similar a algunos juegos del arte moderno (Fig. 1. A).Y en Rouffignac (Plassard 1999: 72, fig. 89) y Le Portel las figuras individuales juegan con las formas naturales de la caverna para convertirlas en dos ojos o un pene erecto. Aunque el caso de Ker de Massat, que Barrière (1990: 59, fig. 38) interpreta como un cuerpo de bisonte transformado en cabeza grotesca, es un poco diferente, pues el ojo de la cabeza está inserto en el cuerpo del bisonte.

En las figuras que comparten elementos gráficos hemos incluido la cabeza humana de la cueva de Ambrosio, aunque esta representación conviene tomarla con prudencia. Es necesario mencionar que se trata de un hallazgo reciente de Ripoll y Muñoz y sería aconsejable esperar un estudio pormenorizado de esta representación. No obstante en Ambrosio se observa el mismo juego temático de ojo humano-nariz animal que en la pieza de La Marche. Esta peculiaridad de la grafía de La Marche no pasó desapercibida para Pales y Tassin de Saint-Péreuse (1976: ob. 29, pl. 66) que la describieron como un ojo que cumple dos roles inscrito en la nariz de un cuadrúpedo. En la caverna de Fontanet la representación de un humano inserto en un bisonte (Tosello y Fritz 2005: 17) presenta un grabado circular que pudiera ser tanto el ojo del humano como el ano del bisonte.

Las figuras individuales de Le Portel y Rouffignac integran relieves rocosos para otorgarles una significación. El itifálico de Le Portel, de aspecto ventrudo y patizambo (Beltrán et al. 1966: 85), tiene una además una expresión alegre en el rostro (sonrisa). 


\begin{tabular}{|l|l|c|l|}
\hline \multicolumn{1}{|c|}{ YACIMIENTO } & \multicolumn{1}{|c|}{ FIGURA/S } & $\begin{array}{c}\text { ELEMENTO } \\
\text { COMPARTIDO }\end{array}$ & \multicolumn{1}{|c|}{ DOBLE SENTIDO } \\
\hline Ambrosio & Cabeza humana y bóvido & Grafía circular & $\begin{array}{l}\text { Ojo humano y nariz de } \\
\text { bóvido }\end{array}$ \\
\hline Fontanet & Humana y bisonte & Grafía circular & $\begin{array}{l}\text { Ojo humano y ano de } \\
\text { bisonte }\end{array}$ \\
\hline Ker de Massat & Bisonte y ¿cabeza grotesca? & Grafía circular & $\begin{array}{l}\text { Ojo de cabeza en cuer- } \\
\text { po de bisonte }\end{array}$ \\
\hline La Marche & Cabeza humana y cabra & Grafía circular & $\begin{array}{l}\text { Ojo humano y nariz de } \\
\text { cabra }\end{array}$ \\
\hline Le Portel & Humano & Estalagmita & $\begin{array}{l}\text { Estalagmita y pene } \\
\text { erecto }\end{array}$ \\
\hline Rouffignac & Caballo & Grieta rocosa & Grieta y ojos \\
\hline
\end{tabular}

Tabla 2.- Figuras de doble sentido.

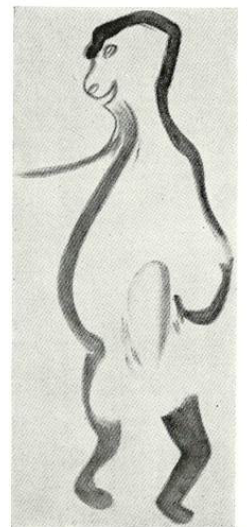

A

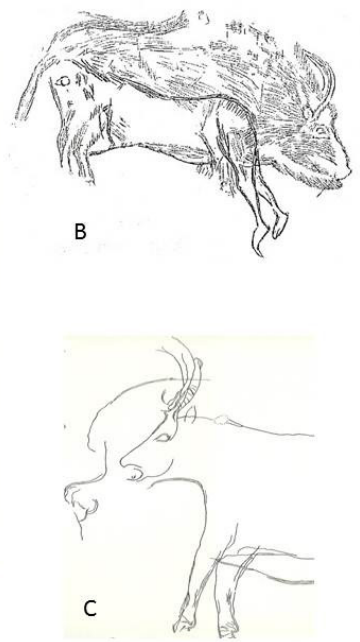

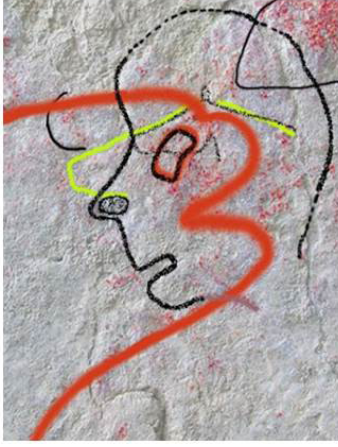

D

Figura 3.- Juegos gráficos con doble sentido. A. Cueva de Le Portel, antropomorfo que utiliza una gran estalagmita como pene (Beltrán et al. 1966: 83, lám. XXXVII, nº 23). B. Cueva de Fontanet, el ojo puede ser atribuido tanto al humano como al ano del bisonte (Tosello y Fritz 2005: 17, fig. 6). C. Pieza de arte mueble de La Marche, un mismo grabado puede representar al mismo tiempo el ojo de la cabeza humana y la nariz de la cabra (Pales y Tassin de Saint Péreuse 1976, ob. 25, pl. 52). D. Ambrosio, detalle parietal de las cabezas humana y animal que parecen compartir un mismo elemento gráfico, en http://paleorama.wordpress.com/2012/06/26 (acceso 18/07/2013).

\section{Las bromas}

En el arte paleolítico encontramos algunas representaciones bastante incongruentes $y$ exageradas que podrían estar relacionadas con una broma de tipo escatológico. En la cueva de Combarelles un antropomorfo inclinado presenta un trazo elíptico en la zona del ano (Fig. 4. D). Del mismo modo, en la caverna de Altxerri un antropomorfo inclinado (y con un enorme falo) presenta un grabado similar en la misma zona (Fig. 4. C). Estos grabados han sido interpretados de diversas maneras (Altuna y Apellániz 1976: 58; Duhard 1996: 86), pero nunca como materia fecal. Otros antropomorfos inclinados con trazos grabados en la zona del ano los encontramos en la cueva de Gabillou (Gaussen 1964: pl. 7. 1) y en un pequeño fragmento de esquisto de Gourdan $(48140 / \mathrm{I} \mathrm{MAN})^{3}$.

La representación de materia fecal pudiera no ser extraña en las representaciones artísticas paleolíticas (p. e. Barrière 1990: 303, fig. 304). Sin ánimo de entrar en la controversia de los propulsores encontramos algunos ejemplos de animales que presentan trazos en el ano, el más sugerente, por sus similitudes formales con los propulsores pirenaicos, es un ciervo retrospiciente de Levanzo (Fig. 4.F). 

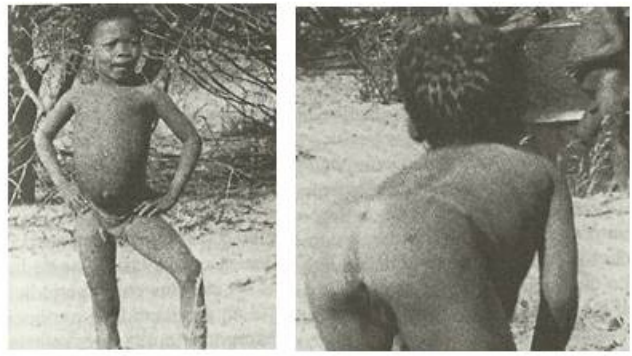

A

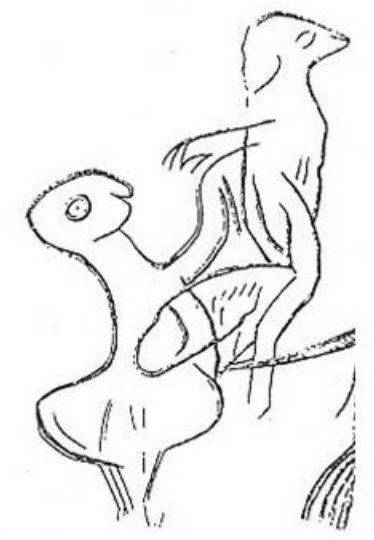

B

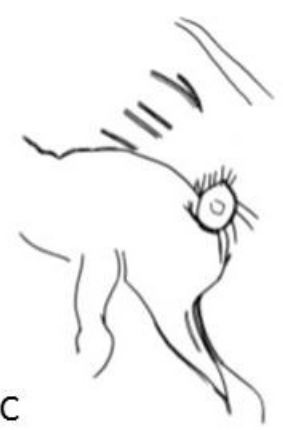

D

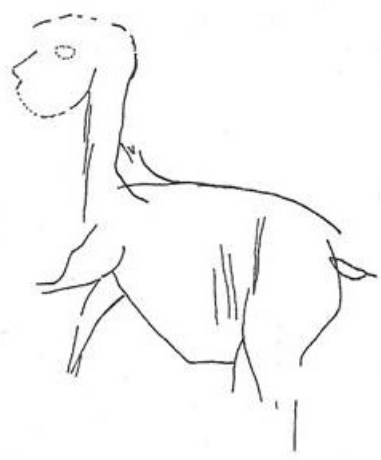

$\mathrm{F}$

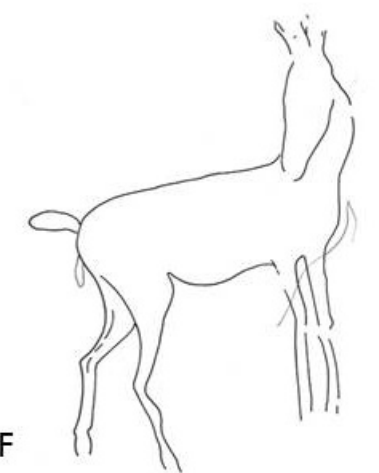

Figura 4.- Bromas. A. Niña bosquimana en posición de reto y burla (Eibl-Eibesfeldt 1993: 365, fig. 4. 64). B. Cueva de Los Casares, un antropomorfo con falo exagerado (Cabré 1940: 87, fig. 4). C. Cueva de Altxerri, una figura humana inclinada (girada mirando a izquierda para su comparación) presenta en el ano un grabado (Altuna y Apellániz 1976: 58, fig. 26). D. Cueva de Combarelles I, detalle del antropomorfo inclinado con un grabado en la zona del ano (Barrière 1997: 272, fig. 261). E. Cueva de Bédeilhac, propulsor de cervatillo con pájaros posados en materia fecal o placenta, dibujo de Bürki en (Bandi 1988: 137, fig. 2). F. Cueva de Levanzo, cierva retrospiciente con un grabado en el ano (Graziosi 1962: fig. 12 y 13).

Otro tipo de representaciones de figuras humanas o antropomorfas presentan un pene exagerado. En la cueva de Casares (Fig. 4. B), el caso ya mencionado de Le Portel (Beltrán et al. 1966: 85), la caverna de Sous-Grand-Lac (Duhard 1996: 78, fig. 53), una estatuilla auriñaciense de Laussel (Duhard, 1996: 63, fig. 40), un canto de esquisto de Lourdes (Duhard 1996: 71, fig. 45) e incluso un humano sonriente de Gourdan (Duhard 1992: 139, fig. 4).

La exhibición anal y la escatología es frecuente motivo de humor entre los pueblos ágrafos. Exhibir el pene o las nalgas es un gesto universal de burla. Todo lo que el pudor suele ocultar como los órganos sexuales y los excrementos son motivo de risa (Blondel 1988: 43). Freud ([1905] 1970: 88-89) advierte del extraordinario éxito que tienen los llamados chistes obscenos, es decir, los que están destinados a mostrarnos una desnudez, y cómo este pudor sexual existe también con los excrementos (Ibid. 83-84). Enseñar el culo emulando la defecación es un gesto universal ampliamente extendido como una burla provocadora. "Las muchachas bosquimanas se inclinan en la propuesta sexual tan profundamente que se alcanza a ver claramente su vagina, mientras que en el caso de la exhibición anal se inclinan menos e incluso, a menudo, retienen arena entre la nalga que dejan caer al inclinarse en alusión clara a la defecación" (Eibl-Eibesfeldt 1993: 537). Enseñar el culo es una broma universal. "El acto tiene un significado exclusivamente agresivo (burla, desprecio o provocación) y en esa función se encuentra difundido por todo el mundo. Las eipo y las yanomami separan en estos casos sus nalgas de tal modo que llega a verse su ano y, cuando les 
es posible, sueltan una ventosidad, un indicio más de que se trata de un acto ritualizado de defecar" (Ibid. 1993: 537). Las nalgas realmente son consideradas como una parte ridícula del cuerpo humano, producto de bromas, risas y alfilerazos (Morris 1986: 77).

Las bromas escatológicas en las sociedades ágrafas son más importantes de lo que pudiera parecer "...los payasos sagrados -que en las ceremonias religiosas pueden romper los tabúes y siempre representan pantomimas obscenas- son iniciados en sus órdenes por medio de una comida ritual de excrementos" (Campbell 1991: 98). Entre los apaches jicarilla de Nuevo México, a los miembros de la sociedad de los payasos se les llama "Excremento Despojado" (Ibid. 1991: 98). Una figura mítica propia casi universal a todas las culturas humanas como el Trickster, que es en muchas culturas el creador del mundo, aparece relacionado con esta broma (Idid. 1991: 308).

Parece que hemos heredado la exhibición fálica de nuestros parientes babuinos y cercopitecos como una muestra de intimidación (Maury 1997: 90). La exhibición del falo es un comportamiento expresivo que muestra una constante y ubicua representación artística (Ibid. 1997: 90). Los payasos dowayos de África gritan obscenidades, exhiben sus partes, provocando la risa de los asistentes a la ceremonia de las calaveras (Barley 2010: 108). Se ha destacado siempre su significado profiláctico; pero en ocasiones tal exhibición aparece en las mitologías de las poblaciones ágrafas vinculada a los Tramposos o Tontos. El Tramposo Maui aparece exhibiendo su pene torcido en las narraciones de la mitología Polinesia (Campbell 1991: 226-227).

\section{Reflexión}

Las piezas reversibles o retruécanos gráficos del Magdaleniense medio/superior muestran cierta uniformidad en la cronología y el formato en cabeza. La orientación de las grafías es también la misma: dos zoomorfos asociados en posición inversa y orientación divergente vertical sobre una misma cara de un objeto mueble. Todo parece indicar que la reversibilidad de la pieza no es fruto de la casualidad, sino de la intención deliberada de jugar con la perspectiva. A primera vista no se captan las formas al revés y el zoomorfo boca abajo queda "oculto" mientras que el zoomorfo boca arriba es percibido en la perspectiva correcta.
La naturaleza de las imágenes de doble sentido es bien diferente a la de las piezas reversibles. Tanto en las figuras que comparten elementos gráficos como en las que aprovechan los relieves naturales de los soportes, el doble sentido no juega con la perspectiva, sino con la forma. Una estalagmita puede ser un descomunal pene erecto $\mathrm{y}$ un grabado circular puede ser un ojo humano y una nariz animal.

Durante el siglo XX no existió una base etnográfica sólida para interpretar el arte paleolítico a partir de los elementos lúdicos asociados a los rituales, las mitologías, la vida cotidiana de las poblaciones ágrafas. Una explicación de tipo sexual o religiosa no es el único camino explicativo a ciertas incongruencias y exageraciones de los elementos gráficos del arte paleolítico. Existen paralelos etnográficos que permiten interpretar la relación entre figura antropomorfa inclinada y materia fecal (grabado en la zona del ano) como una representación gráfica de exhibición anal. La exageración del tamaño del pene en algunos antropomorfos (algunos de ellos con expresiones sonrientes) puede tener un significado jocoso y no sólo sexual o profiláctico.

\section{Conclusiones}

Las piezas de arte mueble reversibles responden bien a la definición de retruécano gráfico. Su disposición no parece ser fruto del azar, ni de una concepción del espacio diferente a la de hoy, sino una búsqueda intencionada de jugar con la perspectiva.

Es necesario matizar las concepciones de retruécano gráfico e imagen reversible de Olins Alpert (1992) basadas en el arte moderno. El material gráfico paleolítico no distingue entre retruécano (la grafía) e imagen reversible (el objeto mueble).Lo reversible es la pieza y el retruécano se produce a nivel gráfico.

El repertorio de figuras de doble sentido es muy escaso para sacar conclusiones, pero, tal y como hemos expuesto, pretenden ser una muestra de las posibilidades de este concepto aplicado por Olins Alpert.

Es necesario tener en cuenta el lado lúdico en la interpretación de vestigios materiales prehistóricos, sin ella nuestros antepasados se quedan desprovistos de aquello que nos hace humanos. 


\section{Agradecimientos}

A Pilar Utrilla, Teresa Andrés, Manuel Bea y Clara Hernando por su ayuda atenta y desinteresada.

\section{Notas}

1. Si el fragmento de la pieza no deja entrever el formato de la figura se recoge tal y como se ha conservado.

2. Sólo pretendemos exponer algunos ejemplos que clarifiquen la definición propuesta. Obsérvense más casos de figuras que comparten elementos gráficos en Olins Alpert (1992). Destaca un juego gráfico de dos cabezas animales que comparten una misma nariz en Lascaux (Ver Vialou 1979: 263, fig. 260) o "le jeu grapique" que menciona Omnes (1984: 23, pl. 4) en la cueva de Labastide.

3. También interpretables como colas.

\section{Referencias Bibliográficas}

Altuna, J.; Apellániz, J.M. (1976): Las figuras rupestres paleolíticas de la cueva de Altxerri (Guipúzcoa). Munibe, 28(1-3).

AzÉma, M. (1992): La représentation du mouvement dans l'art animalier paléolithique des Pyrénées. Bulletin de la Société préhistorique de l'Ariège-Pyrénées, 47: 19-76.

BAHn, P.G. (2003): Líbrenme del último trance: Una valoración del mal uso del chamanismo en los estudios de arte rupestre. El arte prehistórico desde los inicios del siglo XXI(R. de Balbín Behrmann; P. Bueno Ramírez, eds.), Asociación Cultural de Amigos de Ribadasella, Cantabria: 53-75.

Balbín Behrmann, R. (2005): Los cazadores de la Cantabria glacial y su expresión gráfica. El arte mueble paleolítico de Cantabria en su contexto (P.Arias Cabal;R. Ontañon Peredo, eds.), Instituto Internacional de Investigaciones Prehistóricas de Cantabria, Oviedo: 23-36.

Balbín Behrmann, R.; Alcolea González, J.J. (1999): Vie quotidienne et vie religieuse. Les sanctuaires dans l'art paléolithique. L'Anthropologie, 103(1): 23-49.

BANDI, H.G. (1988): Mise en bas et non défécation. Nouvelle interprétation de trois propulseurs magdaléniens sur des bases zoologiques, éthologiques et symboliques. Espacio, Tiempo y Forma, I: 133-147.

BARANDARIÁN, I. (1984): Utilización del espacio y proceso gráfico en el arte mueble paleolítico. ScriptaPraehistorica Francisco Jorda Oblata: Acta Salmanticensia, Salamanca: 113-161.

BARANDIARÁN, I. (2003): Grupos homoespecificos en el imaginario mobiliar magdaleniense. Retratos de familia y cuadros de género. Veleia series minor, 21. Universidad del País Vasco, Victoria.

BARley, N. (2010): El antropólogo inocente. Anagrama, Barcelona.

Barrière, C. (1990): L'art pariétal du Ker de Massat. Presses Universitaires du Mirail, Toulouse.

Barrière, C. (1997): L'art pariétal des grottes les Combarelles. Ampra/Paleo, Angoulême.

BÉgouën, H. (1929): The Magic Origin of Prehistoric Art. Antiquity, 3(9): 5-20.

Beltrán, A.; Robert, R.; Vezian, J. (1966): La cueva de Le Portel. Monografías Arqueológicas 1 (Anejo de Caesaraugusta), Zaragoza.

Blondel, E. (1988): Le risible et le dérisoire. Presses Universitaires de France, Paris.

Breuil, H. (1914): A propos des masques quaternaires. L'Anthropologie, 25: 420-422.

Breuil, H. (1974): Quatre cents siècles d'art pariétal. Les cavernes ornées de l'âge du renne. Centre d'études de documentation préhistoriques, Montignac.

CABré, J. (1940): Figuras antropomorfas en la cueva de los Casares (Guadalajara). Archivo Español de Arqueología, 14: 81-96.

Campbell, J. (1991): Las máscaras de Dios: Mitología primitiva. Tomo 1. Alianza, Madrid.

CAmps, G. (1984): La défécation dans l'art paléolithique. La contribution de la zoologie et de l'éthologie a l'interprétation de l'art des peuples chausseurs préhistoriques (H-G. Bandi, X. Huber; M-R. Sauter; B. Sitter, eds.), Editions Universitaires, Fribourg: 251-261.

CAPitan, L. (1923): Les manifestations ethnographiques et magiques sur les parois de la grotte de Montespan. Revue Anthropologique, 33: 546-551. 
Capitan, L.; Breuil, H.; Peyrony, D. (1924): Les Combarelles aux Eyzies (Dordogne). Masson et Cie,Paris. CArpenter, E. (1980): If Wittgenstein Had Been an Eskimo. Natural History, 89(2): 72-77.

Cartailhac, E.; Breuil, H. (1905): Les peintures et gravures murales des cavernes pyrénéennes. L'Anthropologie, 16: 431-444.

Cartailhac, E.; Breuil, H. (1906): La caverne d'Altamira à Santillane, près Santander (Espagne). Monaco.

Clottes, J. (2001): Le thème mythique du faon à l'oiseau dans le Magdalénien pyrénéen. Bulletin de la Société Préhistorique Ariège-Pyrénées, 56: 53-62.

Cook, A.B. (1903): Les galets peints du Mas d'Azil. L'Anthropologie, 14: 655-660. Corchón, S. (1986): El Arte mueble Paleolítico Cantábrico: contexto y análisis interno. Centro de Investigación y Museo de Altamira, Monografías, 16. Ministerio de Cultura, Madrid.

Delporte, H. (1990): L'image des animaux dans l'art préhistorique. Picard, Paris.

Delluc, B.; Delluc, G. (2009): Art paléolithique en Périgord. Les représentations humaines pariétales. L'Anthropologie, 113: 629-661

Driessen, H. (1999): Humor, risa y trabajo de campo: apuntes desde la antropología. Una historia cultural del humor. Desde la Antigüedad hasta nuestros días. (J. Bremmer; H. Roodenburg, eds.), Sequitur, Madrid: 227-246.

Duhard, J.P. (1992): Les humains ithyphalliques dans l'art paléolithique. Bulletin de la Société Préhistorique de l'Ariège-Pyrénées, 47: 133-159.

Duhard, J.P. (1996): Réalisme de l'image masculine paléolithique. Jérôme Millon, Grenoble.

Eibl-Eibesfeldt, I. (1993): Biología del comportamiento humano. Manual de etología humana. Alianza, Madrid.

Evans-Pritchard, E.E. (1988): Las teorías de la religión primitiva. Siglo veintiuno, Madrid.

FernÁndez Martínez, V.M. (1997): Desenterrando la risa: una aproximación a la arqueología y el humor. Complutum, 8: 335-368.

Freud, S. (1970 [1905]): El chiste y su relación con lo inconsciente. Alianza, Madrid.

FrITZ, C. (1999): Le gravure dans l'art mobilier magdalénien. Du geste à la représentation. Maison des sciences de l'Homme, Paris.

FuČKovÁ, E. (1987): I « divertimenti » praghesi. Effetto Arcimboldo. Trasformazioni del volto nel sedicesimo e nel ventesimo secolo. Bompiani. Milano: 121-133.

Fuentes, O. (2010): Les représentations humaines au magdalénien en Poitou-Charentes. Préhistoire entre Vienne et Charente. Hommes et sociétés du Paléolithique (J. Buisson-Catil; J. Primault, eds.), Association des Publications Chauvinoises. Mémoire 38: 383-396.

Gaussen, J. (1964): La grotte ornée de Gabillou (Près Mussidan, Dordogne). Delmas, Bordeaux.

Giedion, S. (2003 [1964]): El presente eterno, los comienzos del arte: una aportación al tema de la constancia y el cambio. Alianza, Madrid.

GonzÁlez Sainz, C. (2005): El punto de vista de los autores estructuralistas: a la búsqueda de un orden en las cuevas decoradas del Paleolítico Superior. El significado del Arte Paleolítico (J.A. Lasheras Corruchaga; J. González Echegaray, eds.), Ministerio de Cultura, Madrid: 181-209.

Graziosi, P. (1962): Levanzo. Pitture e incisioni. Sansoni, Firenze.

Halverson, J. (1987): Art for Art's Sake in the Paleolithic. Current Anthropology, 28(1): 63-71.

Hernando Álvarez, C. (2013): El sonido de Altamira y los silencios del Côa. Complutum, 24(1): 41-58.

Huizinga, J. (1968): Homo ludens. Alianza, Madrid.

KirCHNER, H. (1952): Ein archäologischer Beitrag zur Urgeschichte des Shammanismus. Anthropos, 47: $244-286$.

Koestler, A. (1964): The Act of Creation. Hutchinson, London.

Lartet, E.; Christy, H. (1992 [1864]): Sur des figures d'animaux ou sculptées et autres produits d'art et d'industrie rapportables aux temps primordiaux de la période humaine. L'invention de la préhistoire. Une anthologie. (N. Richard, ed.), Pocket, Anglaterre: 245-285.

Laurent, P. (1965): Heureuse Préhistoire. Pierre Fanlac, Périgueux.

LÁzničKovÁ-GonYŠEvovÁ, M. (2002): Art mobilier magdalénien en matières dures animales de Moravie (République tchèque). Aspects technologique et stylistique. L'Anthropologie, 106: 525-564.

Leroi-Gourhan, A. (1971): Préhistoire de l'Art Occidental. LucienMazenod, Paris. 
Leroi-Gourhan, A. (1983): Los primeros artistas de Europa. Encuentro, Madrid.

Leroi-Gourhan, A. (1984): Símbolos, arte y creencias de la Prehistoria. Istmo, Madrid.

LuQuet, G.H. (1926): L'art et la religion des hommes fossiles. Masson et Cie, Paris.

Maringer, J. (1962): Los dioses de la Prehistoria. Las religiones en Europa durante el Paleolítico. Destino, Barcelona.

Martínez Bea, M. (2001-2002): El aprovechamiento de accidentes naturales en el arte rupestre paleolítico: un nuevo caso en la cueva del Castillo (Puente Viesgo). Salduie, 2: 27-44.

Martínez Bea, M. (2002): El acondicionamiento del soporte en el arte rupestre paleolítico. Trabajo para la obtención del DEA. Universidad de Zaragoza, Zaragoza.

Maury, J. (1997): Les gestes de l'exhibition phallique et de la main ouverte dans l'art préhistorique. Bulletin de la Société de l'Ariège, 32: 89-99

Moro Abadía, O.; GonzÁlez Morales, M.R. (2005): “El Arte por el Arte”: Revisión de una teoría historiográfica”. Munibe, 57: 179-188.

Moro Abadía, O.; González Morales, M.R. (2006): La idea de progreso en el estudio del arte parietal paleolítico. Zephyrus, 59: 155-162.

Morris, D. (1986): El zoo humano. Orbis, Barcelona.

Nougier, L.R.; Robert, R. (1968): Scène d'initiation de la grotte de La Vache à Alliat (Ariège). Bulletin de la Société préhistorique de l'Ariège-Pyrénées, 23: 13-99.

Obermaier, H. (1932): El hombre prehistórico y los origenes de la humanidad. Revista de Occidente, Madrid.

Olins Alpert, B. (1992): Des preuves de sens ludique dans 1'art au Pléistocène Supérieur. L'Anthropologie, 96(2-3): 219-244

OMnes, J. (1984): Le sanctuaire magdalénien de la grotte de Labastide (Hautes-Pyrénées. France). Munibe, 36: 19-26.

Palacio-PÉRez, E. (2010): Salomon Reinach and the religious interpretation of Paleolithic art. Antiquity, 84: 853-863.

Pales, L.; Tassin de Saint-Péreuse, M. (1976): Les gravures de La Marche. II. Les Humains. Ophrys, Paris.

Pales, L.; Tassin de Saint-Péreuse, M. (1979): L'abri Durif a Enval (Vic-le-Comte, Puy-de-Dôme) II gravures et sculptures sur pierre. Gallia Préhistoire, 22(1): 113-142.

Péquart, M.; Péquart, St.-J. (1963): Grotte du Mas d'Azil (Ariège). Une nouvelle galerie magdalénienne. Annales de Paléontologie, 49: 257-351.

Piette, E. (1907): L'art pendant l'Âge du Renne. Masson et Cie, Paris.

Plassard, J. (1999): Rouffignac. Le sanctuaire des mammouths. Seuil, Paris.

Puche Navarro, R; Lozano Hormaza H. (2002): El sentido del humor en el niño: estudio empírico. Siglo del Hombre, Bogotá.

Radin, P. (1969): The Trickster: A Study in American Indian Mythology. Greenwood Press, New York.

Richard, N. (1993): De l'art ludique a l'art magique. Interprétations de l'art pariétal au XIX ${ }^{\mathrm{e}}$ siècle. Bulletin de la Société Préhistorique Française, 90(1-2): 60-68.

Real Academia Española (2001): Diccionario de la Lengua Española. Espasa Calpe. Madrid.

REINACH, S. (1903): L'art et la magie à propos des peintures et des gravures de l'âge du renne. L'Anthropologie, 14: $257-266$.

RheIms, M. (1987): Principe dei capricci pittorici. Effetto Arcimboldo. Trasformazioni del volto nel sedicesimo e nel ventesimo secolo. Bompiani, Milano: 111-121.

Robert, R. (1953): Le Faon à l'oiseau. Tête de propulseur sculptée du Magdalénien de Bédehilhac. Bulletin de la Société Préhistorique de l'Ariège, 7: 11-18.

Ruiz Redondo, A. (2011): Convenciones gráficas en el arte parietal del Paleolítico cantábrico. La perspectiva de las figuras zoomorfas. Trabajos de Prehistoria, 68, 2: 259-274.

SAInt-PÉrier, R. DE (1930): La grotte d'Isturitz I. Le Magdalénien de la Salle de Saint-Martin. Archives de l'Institut Paléontologie Humaine mémoire 17. Masson et Cie, Paris.

SAInt-PÉrier, R. DE (1936): La grotte d'Isturitz II. Le Magdalénien de la Grande Salle. Archives de l'Institut Paléontologie Humaine mémoire 17. Masson et Cie, Paris.

Sanchidrían, J.M. (2001): Manual de Arte Prehistórico. Ariel Prehistoria, Barcelona. 
Sauvet, G., Tosello, G. (1999). Le mythe paléolithique de la caverne. Le Propre de l'Homme. Psychanalyse et préhistoire. Psychanalyse et préhistoire. (F. Sacco y G. Sauvet, eds.), Delachaux et Niestlé, Lausanne: 55-90.

Sievering, A. (1987a): A Catalogue of Paleolithic Art in the British Museum. The Trustees of the British Museum by British Museum Publications, London.

SieveKInG, A. (1987b): Engraved Magdalenian Plaquettes. A regional and stylistic analysis of Stone, bone and antler plaquettes from Upper Palaeolithic site in France and Cantabric Spain, BAR International Series 369. Archaeopress, Oxford.

SieveKING, A. (1988): Animaux en action: un groupe de plaquettes gravées à identité thématique appartenant au Magdalénien tardif. L'Anthropologie, 92. 1: 41-51.

Tosello, G. (2003): Pierres gravées du Périgord magdalénien. Art, symboles, territoires. XXXVe supplément à Gallia Préhistoire. C.N.R.S., Paris.

Tosello, G.; Fritz, C. (2005): «La Vénus et le Sorcier». Les figurations humaines pariétales au Magdalénien. Bulletin de la Société Préhistorique de l'Ariège-Pyrénées, 60: 7-24.

Utrilla, P; Mazo, C. (1996): Arte mueble sobre soporte lítico de la cueva de Abauntz. Su aportación a los estilos del Magdaleniense Tardío. Complutum (Homenaje a Manuel Fernández Miranda), 6(I): 41-62.

Utrilla, P.; Mazo, C.; Sopena, M.C.; Domingo, R; Martínez Bea, M. (2007-2008): Ríos, montañas y charcas: una representación de paisaje en el bloque 1 de la cueva de Abauntz. Veleia, 24-25: 229-260.

Vialou, D. (1979): Le Passage et l'Abside. Lascaux inconnu. XXIIe supplément à Gallia Préhistoire(A. LeroiGourhan; J. Allain, eds.), C.N.R.S.,Paris:191-301.

Villaverde, V. (1994): Arte paleolítico de la Cova del Parpalló. Estudio de la colección de plaquetas y cantos grabados y pintados. Servei d'Investigació Prehistórica, Valencia.

Welté, A-C. (1988): Note sur une baguette gravée de l'abri de Fontalès (T. \& G.) de la collection Darasse du Museum d' Histoire Naturelle de Toulouse. Bulletin de la Société Préhistorique de l'Ariège Pyrénées, 43: 117-141.

Wernert, P. (1916): Representaciones de antepasados en el arte paleolítico, Comisión de Investigaciones Paleontológicas y Prehistóricas, Memoria 12. Museo Nacional de Ciencias Naturales, Madrid.

WunN, I. (2012): Las religiones en la Prehistoria. Akal, Madrid. 